\title{
Predictive Factors for Occult Contralateral Papillary Thyroid Carcinoma in Patients with Ipsilateral Multifocality on Frozen Biopsy
}

\author{
Ki Nam Park ${ }^{1}$, Se A Lee ${ }^{1}$, Sang Kuk Lee ${ }^{1}$, Jae Hyun Jeong ${ }^{1}$, \\ Sang Woo Sun ${ }^{1}$, Jung Ja Gwak ${ }^{2}$, and Seung Won Lee ${ }^{1}$ \\ ${ }^{1}$ Departments of Otorhinolaryngology-Head and Neck Surgery, ${ }^{2}$ Pathology, Soonchunhyang University College of Medicine, \\ Bucheon, Korea
}

\section{갑상선 일엽 절제술 후 동결절편에서 일측 다발성 갑상선 유두암인 경우 반대측 잠재암 유무의 예측인자}

박기남 ${ }^{1} \cdot$ 이세아 ${ }^{1} \cdot$ 이상국 $^{1} \cdot$ 정재현 $^{1} \cdot$ 선상우 $^{1} \cdot$ 곽정자 $^{2} \cdot$ 이승원 $^{1}$

순천향대학교 의과대학 부천병원 이비인후과학교실, ${ }^{1}$ 병리학교실 ${ }^{2}$

\author{
Received March 29, 2017 \\ Revised June 12, 2017 \\ Accepted June 14, 2017 \\ Address for correspondence \\ Seung Won Lee, MD, PhD \\ Department of Otorhinolaryngology- \\ Head and Neck Surgery, \\ Soonchunhyang University \\ College of Medicine, \\ 170 Jomaru-ro, Bucheon 14584, \\ Korea \\ Tel $+82-32-621-5450$ \\ Fax $+82-32-621-6950$ \\ E-mail1sw0922@naver.com
}

Background and Objectives Papillary thyroid carcinoma (PTC) frequently occurs as multifocal and bilateral tumors. However, multifocality and bilaterality are not easy to detect preoperatively and contralateral remnant tumor might lead to reoperation after hemithyroidectomy. We aimed to demonstrate the frequency of bilaterality and predictive factors for occult contralateral PTC when a frozen biopsy of hemithyroidectomy shows multifocal PTCs in one of the lobes.

Subjects and Method One hundred and thirty patients with PTC were enrolled in this study. All patients underwent hemithyroidectomy and frozen biopsy, followed by total thyroidectomy because of ipsilateral multifocality. Medical records, pathologic results, and preoperative ultrasound results were reviewed retrospectively. Patients were divided into two groups depending on bilaterality (unilateral or bilateral).

Results Bilaterality was detected in 74 of 130 patients $(56.9 \%)$. Bilateral group showed more number of carcinomas $(3.9 \pm 1.4$ vs. $2.3 \pm 0.9)$ and more tendency of existence of contralateral nodule $(87.8 \%$ vs. $55.3 \%)$. Tumor size of $1 \mathrm{~cm}$ or more and contralateral nodules were significant predictive factors for the existence of occult contralateral PTC. The suspicious sonographic feature of contralateral nodule had $75.7 \%$ sensitivity and $75 \%$ specificity for detecting bilaterality.

Conclusion The incidence of bilateral PTC is high in patients with ipsilateral multiple tumors. When the frozen biopsy result shows multifocality in one of the lobes, the remnant tumor may lead to reoperation under recent guidelines on thyroid surgical extent. Characteristics of contralateral nodule can help physicians and patients to make the decision regarding surgical extent.

Korean J Otorhinolaryngol-Head Neck Surg 2017;60(10):517-21

Key Words Frozen sections · Papillary thyroid carcinoma · Thyroid nodule.

This is an Open Access article distributed under the terms of the Creative Commons Attribution Non-Commercial License (http://creativecommons.org/licenses/by-nc/4.0) which permits unrestricted non-commercial use, distribution, and reproduction in any medium, provided the original work is properly cited. 


\section{서 론}

갑상선 유두암은 갑상선에 발생하는 암종 중 가장 흔하며 전 세계적으로 유병률이 증가하고 있다.1) 갑상선 유두암은 다 발성으로 발견되는 병리학적 특징을 가지고 있으며, 검사 방 법에 따라서 18 87\%의 빈도로 보고되고 있다. ${ }^{2-6)}$ 다발성으 로 발생하는 갑상선 유두암의 특성이 예후에 미치는 영향은 논란의 여지가 있으나,") 보다 공격적인 특성을 가지며 예후가 불량하다는 보고들이 있다. ${ }^{899}$ 2015년 미국 갑상선학회 가이 드라인에 따르면 미세 갑상선암의 경우 일측 절제술 시행을 권고하고 있으나, ${ }^{10)}$ 일측성 다발성 갑상선 유두암의 경우 반대 측 엽에 잠재 유두암의 빈도가 높다고 보고하고 있다. ${ }^{11}$

양측 다발성의 경우 가이드라인에 따라 일엽 절제술만 시행 하였을 때 반대측의 잠복성 갑상선암이 적절히 치료가 되지 않 고, 경과 관찰 도중 발견되어 재수술로 인한 환자의 고통이 불가피하다. 이상에서 본 연구자들은 임상에서 흔히 시행되고 있는 동결절편에서 일측 다발성 갑상선암이 확인된 경우 반대 측에 잠재암이 존재하는 빈도 및 예측 인자에 대해 알아보고 자 하였다.

\section{대상 및 방법}

2006년 10월부터 2014년 1월까지 갑상선 유두암으로 진단받 고 치료받은 1186 명 환자의 의무기록을 후향적으로 분석하였 다(기관생명윤리위원회 승인번호 2017-02-001-002). 본원에 서는 갑상선 유두암 의심하에 수술하는 경우 모든 환자에서
동결절편 검사를 시행하고 있다. 일측 갑상선절제술을 시행하 고 동결절편 검사에서 일측 다발성 유두암으로 확인되어 갑 상선 전절제술을 시행한 총 130 명의 환자를 본 연구의 대상으 로 포함하였고, 모든 환자는 최종 병리 검사 결과 갑상선 유두 암으로 확진되었다.

동결절편 검사는 병리과 의사에 의해 검체를 2 3 mm 두 께로 조각(slice)을 내어 각각 조각에서 종양의 존재를 육안적 으로 확인하고 동결 고정 후 슬라이드를 제작하여 종양 존재 여부를 확인하였다(Fig. 1).

수술 전 초음파에서 일측 단발성 또는 다발성 의심으로 미 세세침 검사로 한 개의 결절이 갑상선암으로 진단된 환자를 대상으로 하였고, 동결절편 검사에서 일측 다발성으로 진단 되어 전절제술을 시행한 경우를 대상군에 포함하였으며, 반 대측 결절이 존재하는 경우 초음파에서 중간/높은 의심 결절 인 경우라도, 미세세침 검사로 갑상선암이 진단되지 않은 경 우에는 포함하여 분석하였다.

동결절편 검사에서 단일 병소이거나 동결절편 검사를 시행 하지 않은 경우, 일엽 절제술만 시행한 경우, 수술 전 여러 번의 미세세침 검사를 통해 일측 다발성 또는 반대측 갑상선암이 증명된 경우 및 갑상선 양성 질환이나 유두암이 아닌 다른 아 형의 암종인 경우는 연구에서 제외하였다.

연구 대상을 일측성 다발성 유두암군(일측성 군, Unilateral) 과 양측성 다발성 유두암 군(양측성 군, Bilateral)으로 나누어 두 군에서 성별/연령 등의 임상적 특성과, 술전 초음파 영상 자료 및 동결절편 및 최종 병리 결과 자료를 분석하였다. 술 전 초음파 영상에서 반대측 갑상선 결절은 Korean Thyroid

Fig. 1. Frozen biopsy technique of left hemithyroidectomy specimen. Specimen of left thyroidectomy with ipsilateral central neck dissection (A). Whole specimen was sliced with 2-3 mm thickness and occult multifocal tumor was detected in blue circle (B). Tumor was detected in gross inspection in blue circle (C). Frozen section was made for microscopic evaluation (D).

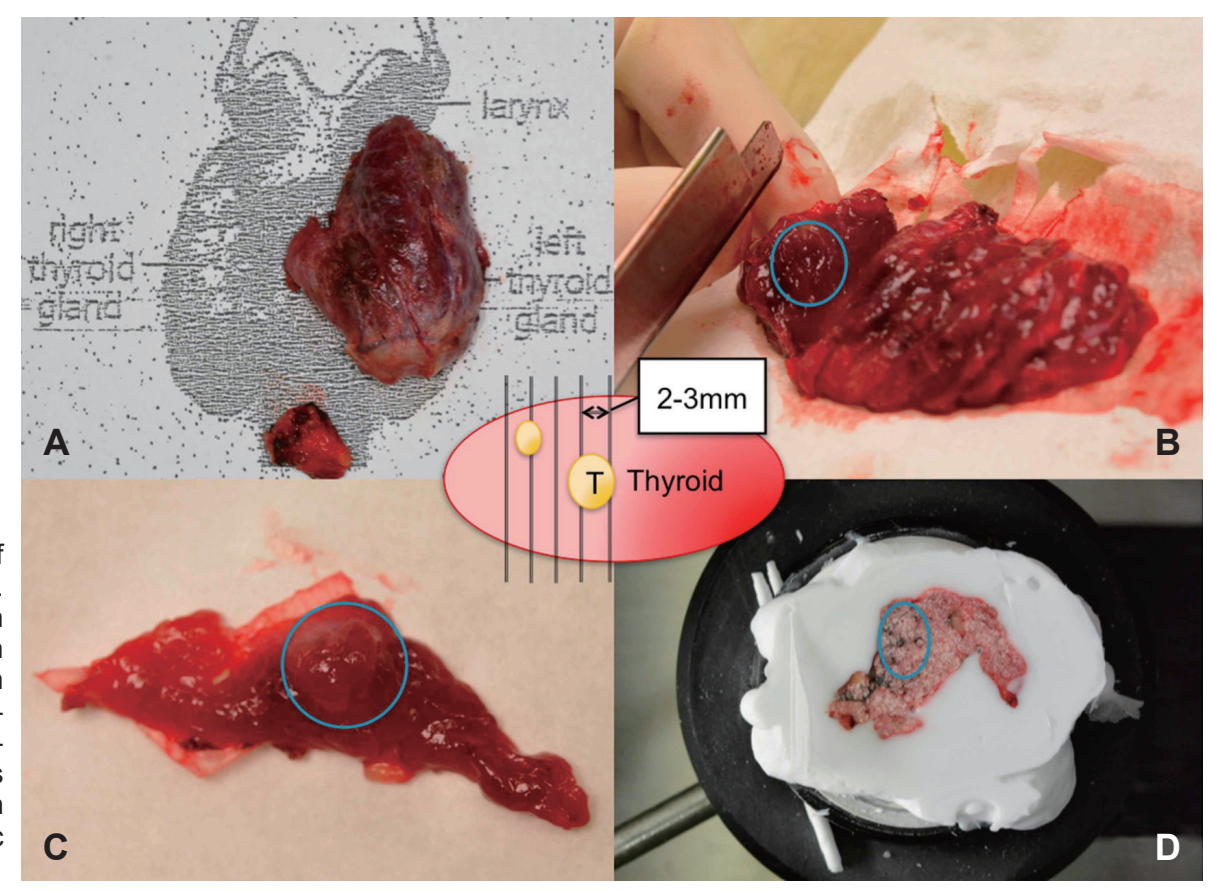


Imaging Reporting and Data System(K-TIRADS) ${ }^{12}$ 을 기준 으로 결절이 아닌 경우(category 1), 양성 시사 결절(category 2,3 ), 중간 의심 결절(category 4) 및 높은 의심 결절(category 5)로 나누어 분석하였다.

통계학적 분석은 임상적 특징, 병리 검사 결과 및 술전 초음 파 특성에 대해 Student's t-test 및 chi-square 검정을 시행하 였고, 양측성 갑상선 유두암의 예측 인자 분석에는 로지스틱 회귀분석(Logistic regression analysis)을 시행하였다. SPSS (version 18.0 for windows; SPSS Inc., Chicago, IL, USA)를 사용하여 유의 수준이 0.05 미만인 경우를 통계학적으로 유 의한 것으로 판정하였다.

\section{결 과}

총 130 명의 환자 중 동결절편에서 일측성 다발성 갑상선 유두암의 결과를 얻은 환자 중 반대측 엽에 수술 전에 확인되 지 않았던 유두암이 최종 병리 결과에서 확인된 경우는 72예 로 $56.9 \%$ 였다. 이 결과를 토대로 일측성 군 $(n=56)$ 과 양측성 군 $(n=72)$ 으로 나누어 임상적, 수술 전 초음파 특징을 Table 1 에 요약하였다.

평균 연령은 일측성 군과 양측성 군에서 각각 49.3( \pm 11.5$)$, 48.2( \pm 10.0$)$ 세였고 $(p=0.546), 45$ 세 이상과 45 세 미만의 빈도
도 차이가 없었다 $(p=0.945)$. 성별은 여성이 각각 $83.9 \%, 64.9 \%$ 였다 $(p=0.982)$. 종양의 크기는 일측성 군은 $9.9( \pm 5.5)$, 양측성 군은 $12.0( \pm 7.0) \mathrm{mm}$ 로 통계적으로 유의한 차이는 없었고 $(p=0.062), 1 \mathrm{~cm}$ 미만의 미세암과 $1 \mathrm{~cm}$ 이상인 종양의 빈도 는 통계적으로 유의한 차이가 없었다 $(p=0.095)$. 수술 전 진 단된 종양의 위치도 양 군에서 차이가 없었다 $(p=0.773)$. 양측 림프절 청소술을 시행한 빈도는 일측성 군에서 $21.4 \%$, 양측 성 군에서 $14.9 \%$ 로 통계적 차이는 없었다 $(p=0.361)$.

총 종양의 개수는 양측성 군에서 $3.9( \pm 1.4)$ 개로 일측성 군 $2.3( \pm 0.9)$ 개에 비해 유의하게 많았다 $(p<0.001)$. 술전 초음파 에서 종양 반대측 엽에 결절이 존재하는 빈도는 양측성 군에 서 $87.8 \%(\mathrm{n}=65)$ 로 일측성 군 $55.3 \%(\mathrm{n}=31)$ 에 비해 통계적으로 유의하게 높았으며 $(p<0.001)$, 양측성 군에서 술전 초음파에 서 발견되지 않은 9명의 환자 중 3명은 동반된 갑상선염(lymphocytic thyroiditis)으로 확인이 안 된 경우이고, 6명은 5 $\mathrm{mm}$ 미만의 작은 결절인 경우였다. 두 군에서의 병리학적 결 과 차이를 분석하였을 때, 갑상선염의 동반 여부나 림프혈관 침범(lymphovascular invasion) 여부는 차이가 없었고, 갑상 선 유두암 아형의 빈도도 통계적으로 유의한 차이가 없었다. 미세 갑상선 피막외 침범의 빈도는 일측성 군에서 $62.5 \%$, 양측 성 군에서 $70.3 \%$ 였고 $(p=0.452)$, 갑상선 주변 근육 침범을 포함 한 거시 피막외 침범은 일측성 군 $10.7 \%$, 양측성 군 $14.9 \%$ 로

Table 1. Patient demographics and clinical characteristics

\begin{tabular}{|c|c|c|c|}
\hline Characteristics & Unilateral $(n=56)$ & Bilateral $(n=72)$ & $p$ value \\
\hline Age & $49.3 \pm 11.5$ & $48.2 \pm 10.0$ & 0.546 \\
\hline Age $(<45: \geq 45)$ & $20: 36$ & $26: 48$ & 0.945 \\
\hline Gender (M:F) & $9: 47$ & $12: 62$ & 0.982 \\
\hline Tumor size (mm) & $9.9 \pm 5.5$ & $12.0 \pm 7.0$ & 0.062 \\
\hline Size $(<1 \mathrm{~cm}: \geq 1 \mathrm{~cm})$ & $34: 22$ & $34: 40$ & 0.095 \\
\hline Tumor location (left:right:isthmus)* & $29: 26: 1$ & $34: 39: 1$ & 0.773 \\
\hline Central node dissection (ipsilateral:bilateral) & $44: 12$ & $63: 11$ & 0.361 \\
\hline
\end{tabular}

*location of preoperative proved carcinoma

Table 2. Pathologic characteristics according to bilaterality

\begin{tabular}{lccc}
\hline \multicolumn{1}{c}{ Characteristics } & Unilateral $(\mathrm{n}=56)$ & Bilateral $(\mathrm{n}=72)$ & $\mathrm{p}$ value \\
\hline Number of carcinoma & $2.3 \pm 0.9$ & $3.9 \pm 1.4$ & $<0.001$ \\
Existence of contralateral nodule (\%)* & 55.3 & 87.8 & $<0.001$ \\
Lymphocytic thyroiditis (\%) & $20(35.7)$ & $27(35.5)$ & 0.928 \\
Lymphovascular invasion (\%) & 0 & $3(4.1)$ & 0.259 \\
Variant (conventional:others) & $53: 3^{\dagger}$ & $73: 1 \neq$ & 0.433 \\
Microscopic ETE (\%) & $35(62.5)$ & $52(70.3)$ & 0.452 \\
Macroscopic ETE (\%) & $6(10.7)$ & $11(14.9)$ & 0.603 \\
Ipsilateral LN metastasis (\%) & $24(42.9)$ & $42(56.8)$ & 0.156 \\
Contralateral LN metastasis (\%) & $7(12.5)$ & $17(22.8)$ & 0.171 \\
\hline
\end{tabular}

* preoperatively detected nodule by ultrasonography, ttwo cases of follicular and 1 case of soild variant, ‡one case of follicular variant. ETE: extrathyroidal extension, LN: Iymph node 
각각 통계적인 차이는 없었다 $(p=0.603)$. 림프절 전이 빈도는 일측성 전이와 양측성 전이 모두 두 군에서 통계적으로 유의 한 차이는 없었다(Table 2).

양측성 다발성 갑상선암의 존재와 관련된 인자를 분석하였 을 때, 단변량 분석에서는 반대편에 갑상선 결절이 있는 경우 가 유의한 상관성을 보였고, 연령이나 성별, 갑상선 피막외 침 범이나 림프혈관 침범 여부나 갑상선염 동반 여부는 통계학적 으로 유의하지 않았다. 다변량 분석에서는 $1 \mathrm{~cm}$ 이상의 크기 와 반대측 결절 유무가 유의하게 반대측 갑상선암의 존재에 영향을 미치는 것으로 조사되었다(Table 3).

반대측 갑상선 결절의 초음파적 특징은 일측성 군에서 결절 이 아니거나 양성 결절 소견인 경우는 $45 \%, 30 \%$ 였고, 중간 의 심 결절 또는 높은 의심 결절인 경우는 각각 $21 \%, 4 \%$ 였다. 양 측성 군에서는 양성 결절 소견 $12 \%$, 결절이 아닌 경우 $12 \%$, 중 간 의심 결절 $35 \%$, 높은 의심 결절 $41 \%$ 였다. 초음파 결과가 결 절이 아니거나 양성 결절 소견인 경우 양성 소견(benign favor) 으로 높은/중간 의심 결절(indeterminate 또는 suspicious for malignancy)을 악성 소견(suspicious)으로 분류하여 분석하 였을 때, 수술 전 초음파에서 양성 소견이 아닌 경우 갑상선 유 두암의 양측성을 $75.7 \%$ 의 민감도와 $75 \%$ 의 특이도를 가지고 예측할 수 있었다 $(p<0.001)$ (Table 4).

\section{고 찰}

갑상선 유두암은 다발성으로 발생하는 특징을 가지며 개 개 종양의 기원이 갑상선내 전이 병소(intraglandular metastasis)로 여겨지다가,3) 분자 생물학적 분석법의 발달에 따라 동
시 다발적 종양(multiple synchronous tumor)으로 생각되고 있다. ${ }^{2}$ 유두암의 양측성 발생이 예후에 미치는 영향은 논란의 여지가 있으나 임파선 전이의 빈도가 증가한다는 보고 등, 713$)$ 예후에 악영향을 준다는 보고가 많다.

다발성 갑상선암의 수술 전 초음파 민감도는 $42.7 \%$ 이고 양측성 갑상선암에 대해서는 $49 \%$ 였으며, 다발성 병소의 크 기가 일차 종양에 비해 작아 수술 전 진단의 어려움이 있다 고 보고되고 있다. ${ }^{14)}$ 본 연구에서는 다발성 암의 수술 전 진단 의 한계를 극복하고자 갑상선 검체 mapping에 이용된 방법 을 참고하여, ${ }^{15)}$ 수술 중 2 3 mm 간격의 세밀한 동결절편 검 사를 시행하였고, 일측성 다발성 암인 경우 양측성 암일 확 률은 $56.9 \%$ 였다. 물론 동결절편 검사의 비용 효율성은 검증 되지 않았고, 수술 전 미세세침 검사에서 갑상선암이 확인된 경우에는 불필요하다고 보고되고 있으나, ${ }^{16}$ 수술 전 다발성 암을 진단할 수 있는 효율적인 검사법의 부재로 충분한 진단 적 가치를 가진다고 할 수 있다.

본 연구에서는 일측 다발성이 동결절편으로 확인된 경우, 최종 병리 결과에 따라 일측 다발성 및 양측 다발성으로 나누 어 분석하였을 때, 종양의 크기를 포함한 임상적 특징은 두 군에서 차이가 없었다(Table 1). 병리학적 결과 분석에서 암종 의 개수는 양측성이 일측성에 비해 1.6 개 많았고, 수술 전 초 음파에서 반대측에 결절이 발견된 빈도가 $87.8 \%$ 로 $55.3 \%$ 인 일측성에 비해 많았다(Table 2). 다변량 분석에서 $1 \mathrm{~cm}$ 이상 의 종양 크기와 반대측 엽의 술전 초음파에서 존재 여부가 양측성을 예측할 수 있는 인자로 확인되었다. 본 연구의 결 과 중 종양의 크기가 클수록 양측성 암의 확률이 증가하는 결과는 $7 \mathrm{~mm}$ 이상인 경우에 증가한다는 기존 보고와 유사

Table 3. Predictive factors for bilateral papillary thyroid carcinoma

\begin{tabular}{lccc}
\hline \multicolumn{1}{c}{ Variables } & Univariate & Multivariate & Odds ratio \\
\hline Age $(<45: \geq 45)$ & 0.945 & 0.469 & 0.73 \\
Gender $(\mathrm{M}: \mathrm{F})$ & 0.982 & 0.223 & 0.47 \\
Size $(<1 \mathrm{~cm}: \geq 1 \mathrm{~cm})$ & 0.095 & 0.025 & 2.71 \\
Extrathyroidal extension (absent:present)* & 0.351 & 0.365 & 1.47 \\
Lymphovascular invasion & 0.127 & 0.999 & 1.82 \\
Lymphocytic thyroiditis & 0.928 & 0.207 & 1.76 \\
Contralateral nodule & $<0.001$ & $<0.001$ & 10.5 \\
\hline
\end{tabular}

*microscopic and macroscopic

Table 4. Sonographic feature of contralateral nodules and correlation with bilaterality of papillary thyroid carcinoma

\begin{tabular}{llll}
\hline \multicolumn{1}{c}{ Sonographic feature } & Unilateral & Bilateral & \\
\hline Suspicious (K-TIRADS 4:K-TIRADS 5) & $14(2: 12)$ & $56(26: 30)$ & 70 \\
Benign favor (K-TIRADS 1:K-TIRADS 2 and 3) & $42(17: 25)$ & $18(9: 9)$ & 60 \\
\hline Total & 56 & 74 & 130 \\
\hline
\end{tabular}

Sonographic feature of suspicious finding (K-TIRADS category 4 and 5) had $75.7 \%$ sensitivity and $75 \%$ specificity to detect the bilaterality of papillary thyroid carcinoma when the frozen biopsy result was ipsilateral multifocal carcinomas $(p<0.0001)$. K-TIRADS: Korean Thyroid Imaging Reporting and Data System 
하다. ${ }^{17)}$ 또한 양측성 빈도는 $56.9 \%$ 로 수술 전 초음파에서 단 일 병소로 whole-specimen mapping을 시행한 연구의 $30.2 \%$ 와, ${ }^{15)}$ 일측에 2 개인 경우 양측성인 $30.2 \%, 3$ 개인 경우 $46.2 \%$ 였다는 이전 연구 ${ }^{14)}$ 에 비해 높은 빈도로 관찰된다. 이는 전자 연구와 달리 일측 다발성이 동결절편에서 증명된 경우가 연 구 대상이고, 후자 연구에 비해 $1 \mathrm{~cm}$ 이상인 종양이 연구에 포함되어 높은 빈도로 나타났을 것으로 생각된다.

본 연구의 제한점으로는 후향적 분석으로 인한 선택 오류 및 수술 전 초음파에서 반대측에 양성 또는 중간/높은 의심 결절을 가진 환자군이 포함된 점을 들 수 있다. 이로 인해 상 대적으로 일측성에 비해 양측성 군의 빈도가 높으나, 술전 반대측에 양성 또는 의심 결절이 있는 환자들을 제외할 경우 의미 있는 임상 결과를 얻을 수 없고, 임상적으로 수술 전에 반대측 결절에 대한 평가가 종양의 크기나 반복적인 미세세 침 검사의 제한 등으로 충분히 이루어지지 않는 경우가 많아 포함하는 것이 보다 도움이 되는 정보를 제공할 수 있을 것으 로 판단된다.

수술 중 동결절편 검사에서 일측 다발성 갑상선암으로 진 단된 경우, 술전 초음파에서 반대측 엽의 결절이 indeterminate 이상인 경우(suspicious) 반대측 잠재암 존재의 민감도 는 $75.7 \%$, 특이도는 75\%였다(Table 3). 수술 전 모든 갑상선 결절에 대해 미세세침 검사를 시행할 수는 없으며, 미국 갑상 선 가이드라인 2016에 따르면 $1 \mathrm{~cm}$ 이하의 갑상선 결절에 대 해서는 암이 의심되더라도 시행하지 않는 것을 권고하고 있 다. ${ }^{10)}$ 다만 종양의 크기, 주변 조직 침윤 여부 및 림프절 전이 여부에 따른 갑상선 절제 범위에 대한 권고안은 제시하고 있 으나 다발성 갑상선암에 대한 언급은 없어, 임상의로서 흔히 직면하는 고민스러운 상황이라고 할 수 있다.

양측성 갑상선암의 경우 전통적으로는 갑상선 아전 절제술 혹은 전절제술의 적응증으로 여겨지나 예후에 미치는 영향 에 대한 보고는 많지 않다. ${ }^{18)}$ 양측성의 빈도는 $19.9 \%$ 로 보고 하고 있고 예후에 악영향을 준다는 보고가 있어 새로운 잠재 적 예후 인자로 제시되고 있으나, ${ }^{19)}$ 미국 갑상선학회 가이드 라인의 $1 \mathrm{~cm}$ 이하 또는 제한된 $1 \sim 4 \mathrm{~cm}$ 의 갑상선암에 대한 일 엽 절제술 후 병리 결과에서 일측 다발성인 경우 반대측 엽에 종양의 존재 가능성의 예측과 재수술 가능성에 대한 환자 설 명에 본 연구의 결과가 도움을 줄 수 있을 것으로 생각한다.

\section{REFERENCES}

1) Davies L, Welch HG. Increasing incidence of thyroid cancer in the United States, 1973-2002. JAMA 2006;295(18):2164-7.
2) Shattuck TM, Westra WH, Ladenson PW, Arnold A. Independent clonal origins of distinct tumor foci in multifocal papillary thyroid carcinoma. N Engl J Med 2005;352(23):2406-12.

3) Iida F, Yonekura M, Miyakawa M. Study of intraglandular dissemination of thyroid cancer. Cancer 1969;24(4):764-71.

4) Carcangiu ML, Zampi G, Rosai J. Papillary thyroid carcinoma: a study of its many morphologic expressions and clinical correlates. Pathol Annu 1985;20 Pt 1:1-44.

5) Katoh R, Sasaki J, Kurihara H, Suzuki K, Iida Y, Kawaoi A. Multiple thyroid involvement (intraglandular metastasis) in papillary thyroid carcinoma. A clinicopathologic study of 105 consecutive patients. Cancer 1992;70(6):1585-90.

6) Sakorafas GH, Stafyla V, Kolettis T, Tolumis G, Kassaras G, Peros G. Microscopic papillary thyroid cancer as an incidental finding in patients treated surgically for presumably benign thyroid disease. J Postgrad Med 2007;53(1):23-6.

7) Chow SM, Law SC, Chan JK, Au SK, Yau S, Lau WH. Papillary microcarcinoma of the thyroid-Prognostic significance of lymph node metastasis and multifocality. Cancer 2003;98(1):31-40.

8) Qu N, Zhang L, Ji QH, Zhu YX, Wang ZY, Shen Q, et al. Number of tumor foci predicts prognosis in papillary thyroid cancer. BMC Cancer 2014;14:914.

9) Kuo SF, Lin SF, Chao TC, Hsueh C, Lin KJ, Lin JD. Prognosis of multifocal papillary thyroid carcinoma. Int J Endocrinol 2013;2013: 809382.

10) Haugen BR, Alexander EK, Bible KC, Doherty GM, Mandel SJ, Nikiforov YE, et al. 2015 American Thyroid Association Management Guidelines for adult patients with thyroid nodules and differentiated thyroid cancer: the American Thyroid Association Guidelines Task Force on thyroid nodules and differentiated thyroid cancer. Thyroid 2016;26(1):1-133.

11) Koo BS, Choi EC, Yoon YH, Kim DH, Kim EH, Lim YC. Predictive factors for ipsilateral or contralateral central lymph node metastasis in unilateral papillary thyroid carcinoma. Ann Surg 2009;249(5): 840-4.

12) Shin JH, Baek JH, Chung J, Ha EJ, Kim JH, Lee YH, et al. Ultrasonography diagnosis and imaging-based management of thyroid nodules: revised Korean Society of Thyroid Radiology Consensus Statement and recommendations. Korean J Radiol 2016;17(3):370-95.

13) Baudin E, Travagli JP, Ropers J, Mancusi F, Bruno-Bossio G, Caillou B, et al. Microcarcinoma of the thyroid gland: the Gustave-Roussy Institute experience. Cancer 1998;83(3):553-9.

14) So YK, Kim MW, Son YI. Multifocality and bilaterality of papillary thyroid microcarcinoma. Clin Exp Otorhinolaryngol 2015;8(2):174-8.

15) Park SY, Jung YS, Ryu CH, Lee CY, Lee YJ, Lee EK, et al. Identification of occult tumors by whole-specimen mapping in solitary papillary thyroid carcinoma. Endocr Relat Cancer 2015;22(4):679-86.

16) Cetin B, Aslan S, Hatiboglu C, Babacan B, Onder A, Celik A, et al. Frozen section in thyroid surgery: is it a necessity? Can J Surg 2004; 47(1):29-33.

17) Zhou YL, Gao EL, Zhang W, Yang H, Guo GL, Zhang XH, et al. Factors predictive of papillary thyroid micro-carcinoma with bilateral involvement and central lymph node metastasis: a retrospective study. World J Surg Oncol 2012;10:67.

18) Prescott JD, Parangi S. Bilaterality in papillary thyroid carcinoma: does it influence prognosis? Ann Surg Oncol 2012;19(1):1-2.

19) Wang W, Zhao W, Wang H, Teng $X$, Wang $H$, Chen $X$, et al. Poorer prognosis and higher prevalence of BRAF (V600E) mutation in synchronous bilateral papillary thyroid carcinoma. Ann Surg Oncol 2012;19(1):31-6. 